\title{
Quantitative proteomic analysis of cerebrospinal fluid from patients with diffuse large B-cell lymphoma with central nervous system involvement: A novel approach to diagnosis
}

\author{
XIAOBEI LIU ${ }^{1 *}$, FEI MO $^{1}, \mathrm{HAO} \mathrm{ZENG}^{2}, \mathrm{SHAZHU}^{2}$ and XUELEI MA ${ }^{1 *}$ \\ ${ }^{1}$ Cancer Center, State Key Laboratory of Biotherapy; ${ }^{2}$ West China School of Medicine, \\ West China Hospital, Sichuan University, Chengdu, Sichuan 610041, P.R. China
}

Received December 7, 2018; Accepted June 10, 2019

DOI: $10.3892 /$ br.2019.1222

\begin{abstract}
The outcome of patients with diffuse large B-cell lymphoma (DLBCL) with central nervous system (CNS) recurrence is poor. However, there is currently no consensus regarding diagnostic techniques. The aim of the present study was to investigate the cerebrospinal fluid (CSF) protein profile of DLBCL and identify a potential novel method for the early diagnosis of patients with DLBCL at high risk for subsequent CNS involvement. The CSF proteomic profiling of patients with DLBCL and a control group were compared using label-free liquid chromatography-tandem mass spectrometry. Gene Ontology and pathway analyses were conducted using the Database for Annotation, Visualization and Integrated Discovery. The protein interactions were analyzed using the Search Tool for the Retrieval of Interacting Genes/Proteins database. In the present study, a total of 53 differentially expressed proteins with $>1 \log _{2}$ fold change (false discovery rate $<0.01, \mathrm{P}<0.05)$ were identified and quantified. These proteins appeared to be involved in platelet degranulation, innate immune response and cell adhesion. Two hub gene network modules were obtained by protein-protein interaction network analysis. Of these proteins, secreted protein acidic and rich in cysteine (SPARC) and proenkephalin (PENK) were significantly decreased in the CSF of patients with DLBCL, which appeared to be correlated with CNS involvement. The findings of the present study indicate that decreased expression levels of SPARC and PENK in the CSF may serve as early-phase biomarkers to evaluate the risk of CNS involvement in patients
\end{abstract}

Correspondence to: Dr Xuelei Ma, Cancer Center, State Key Laboratory of Biotherapy, West China Hospital, Sichuan University, 37 Guo Xue Alley, Chengdu, Sichuan 610041, P.R. China

E-mail: drmaxuelei@gmail.com

*Contributed equally

Key words: diffuse large B-cell lymphoma, central nervous system involvement, cerebrospinal fluid, mass spectrometry, proteomic analysis with DLBCL, enabling clinicians to offer prophylactic therapy at the time of diagnosis.

\section{Introduction}

Diffuse large B-cell lymphoma (DLBCL) is the most common type of non-Hodgkin's lymphoma (NHL), accounting for $31 \%$ of all cases of NHL in western countries and $>40 \%$ of NHL cases in Asia (1-3). With the currently available options for chemoimmunotherapy and systemic disease control, the 5-year survival rate of patients with DLBCL has improved $(60-90 \%)(4,5)$. Secondary involvement of the central nervous system (CNS) in patients with DLBCL is a relatively uncommon manifestation, encountered in only $5-7 \%$ of cases (6-9); however, its incidence is higher in patients with certain high-risk clinical characteristics at the time of diagnosis (10). These risk factors include a high International Prognostic Index score (11); involvement of more than two extranodal sites, retroperitoneal lymph node involvement, elevated lactate dehydrogenase level, or DLBCL originating from high-risk locations, such as the bone marrow, paranasal sinuses, testis, breast, adrenal gland and kidney (8,12-16). The outcome following CNS relapse is poor, with the overall survival shortened to $<6$ months (17). Intrathecal (IT) and intravenous high-dose (HD) methotrexate are common methods of CNS prophylaxis (11). Given the low CNS relapse rate in DLBCL, and evaluating the benefits against the adverse effects, the application of CNS prophylaxis for DLBCL is not widely implemented $(12,18)$. As it is preferable that CNS prophylaxis is administered during primary chemotherapy, the identification of patients with DLBCL who are at high risk for subsequent CNS recurrence at the time of diagnosis is crucial. There is currently no consensus regarding a diagnostic algorithm for CNS involvement in DLBCL. Neurological symptoms, CNS imaging, stereotactic biopsy and cerebrospinal fluid (CSF) cytology are the current methods commonly used for diagnosis and evaluating patients at high risk of, or with suspected, CNS involvement (19). CSF examination includes cytology, flow cytometric analysis and biochemical biomarkers. CSF cytology is a specific diagnostic approach, but it can only detect malignant lymphoid cells in $40 \%$ of patients with suspected CNS dissemination (20). Flow cytometric analysis of the CSF has already demonstrated 
increased sensitivity (21); however, since the introduction of rituximab, the majority of CNS relapse events are parenchymal (65-70\%), and CSF flow cytometry is of limited diagnostic value in such cases (22-24). Biochemical biomarker examination of the CSF exhibits higher sensitivity compared with CSF cytology (58-85\%), but only a moderate improvement in specificity (85\%) (25). Therefore, it is necessary to develop a convenient and accurate method for evaluating the risk of CNS involvement at diagnosis in order to implement adequate CNS prophylaxis.

Quantitative global proteomics is an advanced approach to the accurate characterization of proteins in complex biological systems, which is applied to identify unbiased biomarkers or key proteins associated with specific physiological and pathological states (26). The advantages of label-free quantification liquid chromatography-mass spectrometry (LC/MS) analysis are as follows: First, the cost, procedure and artificial expenses of labeling samples are eliminated. Second, it has the capacity to quantify a large number of proteins per LC/MS measurement (27). By using proteomics, numerous studies have identified potential CSF biomarkers of neurological diseases, including amyotrophic lateral sclerosis, cerebral malaria and tuberculous meningitis (28-30). Quantitative proteomics of CSF samples from serial lumbar punctures during induction in patients with acute lymphoblastic leukemia have found potential predictive markers of CNS thrombosis (31). However, to the best of our knowledge, global proteomic profiling of CSF from patients with DLBCL has not been reported to date. Therefore, in the present study, a high-throughput label-free quantitative proteomic analysis was performed to identify proteins present in the CSF of patients with DLBCL with CNS recurrence compared with those in healthy controls, in order to identify potential CSF biomarkers for patients at high risk of developing CNS recurrence.

\section{Materials and methods}

Subjects. The subjects included four patients diagnosed with DLBCL at the West China Medical Center of Sichuan University (Chengdu, China), and six healthy control subjects recruited at the Physical Examination Center of West China Hospital, Sichuan University from January 2016 to January 2017. The patients with DLBCL were evaluated for CNS recurrence based on the clinical characteristics at the time of diagnosis. The healthy control subjects were defined as individuals without active DLBCL or any neurological complaints. Informed consent was obtained from all the participants and the study protocol was approved by the Medical Ethics Committee of West China Hospital, Sichuan University.

Sample preparation. The CSF was collected in plastic tubes containing Trasylol (Bayer Diagnostics) to prevent proteolysis. Following clinical analysis, the CSF samples were centrifuged at $3,000 \mathrm{x} \mathrm{g}$ at $4^{\circ} \mathrm{C}$ for $5 \mathrm{~min}$. All supernatant, aside from the last $0.5 \mathrm{ml}$, was transferred to a new container and then immediately frozen at $-20^{\circ} \mathrm{C}$ and stored at $-80^{\circ} \mathrm{C}$ until further use. A total of $30 \mu \mathrm{l} \mathrm{CSF}$ were solubilized in cold RIPA buffer [150 mm NaCl, $50 \mathrm{~mm}$ Tris-HCl (pH 7.61), NP-40, $1 \%$ deoxycholic acid] with phosphatase and protease inhibitors on ice for $10 \mathrm{~min}$. The samples were then centrifuged at
$20,000 \mathrm{x}$ g at $4^{\circ} \mathrm{C}$ for $5 \mathrm{~min}$ and quantified using a Bradford

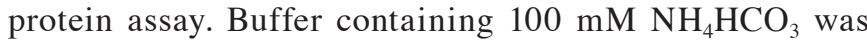
added to equivalent proteins at $100 \mu \mathrm{g}$ for trypsin digestion. The protein samples were then treated with $5 \mathrm{mM}$ DL-dithioreitol (DTT, Sigma-Aldrich; Merck KGaA) and incubated for $60 \mathrm{~min}$ at $37^{\circ} \mathrm{C}$. To alkylate the cysteines, iodoacetamide (IAM; Sigma-Aldrich; Merck KGaA) was added to a final concentration of $15 \mathrm{mM}$, followed by incubation in the dark at room temperature for $45 \mathrm{~min}$. A total of $30 \mathrm{mM}$ L-cysteine (Promega Corporation) was required for blocking redundant IAM. The protein samples were digested with trypsin (Promega Corporation) overnight at $37^{\circ} \mathrm{C}$ at a protein: Trypsin ratio of 50:1. The digestion reaction was terminated by heating the samples to $90^{\circ} \mathrm{C}$ to inactivate the enzyme. Finally, C18 ZipTip (Merck KGaA) was used for desalination of the in-solution digested samples.

MS analysis. Prior to being analyzed by LC-MS/MS, coupling an Easy nLC1000 nanoflow HPLC system to the Q-Exactive quadrupole-orbitrap mass spectrometer (Thermo Fisher Scientific, Inc.), all samples were lyophilized and resuspended in buffer $\mathrm{A}[2 \%$ acetonitrile $(\mathrm{ACN})+0.1 \%$ formic acid (FA)]. A two-column setup was used. Both the trap column $(100 \mu \mathrm{m} \times 2 \mathrm{~cm})$ and analytical column $(75 \mu \mathrm{m} \times 12 \mathrm{~cm})$ were packed in-house with Magic C18 AQ resin (200A, $5 \mu \mathrm{m}$; Michrom Bioresources). The composition (v/v) of the LC buffer was as follows; buffer A: $97.9 \%$ water, $2 \% \mathrm{ACN}$ and $0.1 \% \mathrm{FA}$; and buffer B: $95 \%$ ACN, $4.9 \%$ water and $0.1 \%$ FA. The mobile phases were initially $4 \%$ B for 3 min, reaching $22 \%$ B between 3 and $43 \mathrm{~min}$ at a flow rate of $400 \mathrm{nl} / \mathrm{min}$. An increase to $30 \%$ $\mathrm{B}$ over the next $8 \mathrm{~min}$ was at $300 \mathrm{nl} / \mathrm{min}$. An increase to $95 \% \mathrm{~B}$ occurred between 52 and $60 \mathrm{~min}$ and lasted for the final $5 \mathrm{~min}$. The mass spectrometer was set to perform data-dependent acquisition in positive ion mode. Full MS spectra were acquired at a resolution of 70,000 over a mass range of 350-1,800 m/z. The automatic gain control (AGC) value was set to $3 \times 10^{6}$ with maximum fill times of $20 \mathrm{~ms}$. For the MS/MS scans, the 20 most intense parent ions were selected with a $1.6 \mathrm{~m} / \mathrm{z}$ mass window and fragmented with a normalized collision energy of $27 \%$. The MS/MS spectra were recorded at a resolution of 17,500, with the AGC value target set to $1 \times 10^{6}$ and a maximum fill time of $64 \mathrm{~ms}$. Parent ions with a single charge or with unassigned charge states were not selected for fragmentation, and the intensity threshold for selection was set to $3.1 \times 10^{6}$. Dynamic exclusion with a time window of $30 \mathrm{sec}$ was applied.

Data analysis. The raw files acquired on the Q-Exactive plus were subjected to data analysis using MaxQuant software (version 1.3, https://maxquant.org/). The searches were performed against the SwissProt human database (updated on 05/2012, 86,758 sequences, https://www.uniprot.org/statistics/Swiss-Prot). The following settings were selected for analysis: Cysteine carbamidomethylation was set as a fixed modification. Oxidation of methionine and acetylation of the protein $\mathrm{N}$-terminal were set as variable modifications. Precursor peptide mass deviation was set to $10 \mathrm{ppm}$ and fragment ion mass deviation was set to $0.02 \mathrm{Da}$. The maximum number of missed trypsin cleavages was set to two in the searches. The peptide false discovery rate was calculated with searches against the corresponding reverse database and set to 0.01. Label-free quantification was performed in MaxQuant, 


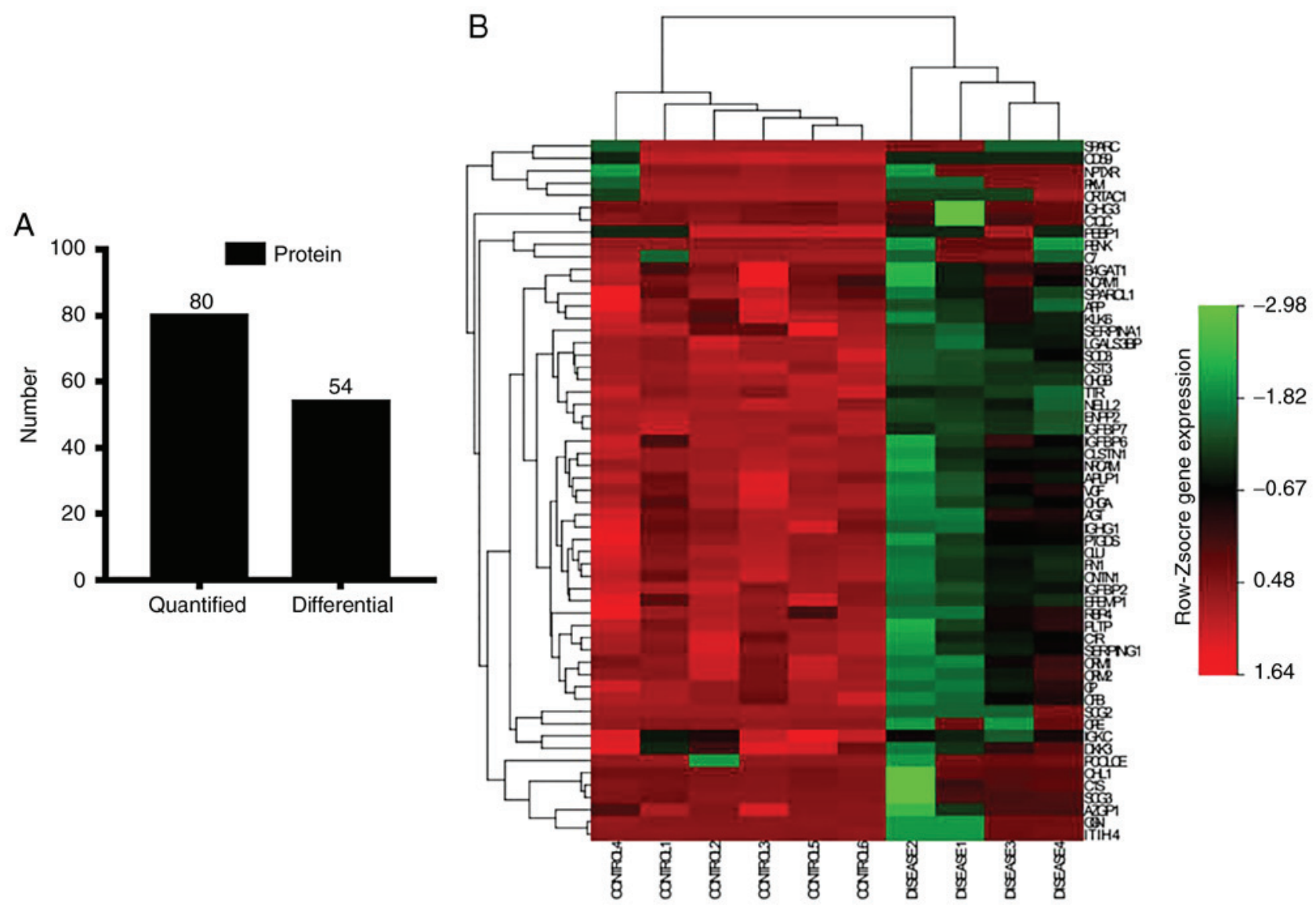

Figure 1. Quantitative proteomics of CSF. (A) Number of all quantified and differential proteins selected. (B) Heat map of the differential proteins. Protein expression values were $\log _{2}$-normalized and cluster analysis was performed using $\mathrm{Z}$-score protein intensities for the proteins with $\mathrm{P}<0.05$. Red indicates a high expression level; green indicates a low expression level. CSF, cerebrospinal fluid.

as described previously (32). Peptides with the same mass but different oxidation states were considered to be the same peptide in all data analyses, in case the oxidation was due to sample manipulation.

Proteomics analysis. The heat map of Global protein expression profiles was carried out by $\mathrm{R}$ version. The enrichment functional analysis for Gene Ontology (GO) terms and KEGG pathways of the identified proteins was performed using David 6.7 (https://david-d.ncifcrf.gov/). The protein-protein interacts network (PPIN) of the proteins selected in this study was constructed by the String database (https://string-db.org/). Then the hub gene network modules from the PPIN were done by MCODE (Cytoscape 3.6.0, https://cytoscape.org/).

Statistical analysis. Statistical analyses were performed with GraphPad Prism 7.0 (GraphPad Software, San Diego,CA, USA) and the data were expressed as mean \pm standard deviations (SD). $\mathrm{P}<0.05$ was considered statistically significant. Multiple comparisons of different groups were performed using paired t-test.

\section{Results}

Subject characteristics. CSF samples were obtained from the four patients with DLBCL with CNS involvement and six healthy controls. The DLBCL group included two men and two women. The mean age of the patients was 45 years (range, 20.25-62.50 years). The healthy control group included three men and three women, with a mean age of 40.5 years (range, 26.50-55.25 years). There were no statistically significant differences between the two groups in terms of age or sex $(\mathrm{P}>0.05)$. The demographic details of the patients with DLBCL are summarized in Table SI.

Quantitative proteomics of CSF. A total of 80 proteins from the four patients and six healthy control subjects were identified using label-free LC-MS/MS, and only 53 differentially expressed proteins with $>1 \log _{2}$ fold change and $\mathrm{P}<0.05$ between the two groups were selected for further analysis (Fig. 1A; Table I). Heat maps of all proteins selected are shown in Fig. 1B. The Database for Annotation, Visualization and Integrated Discovery (DAVID) was utilized for the functional annotation of the 53 differential proteins. According to the Gene Ontology database, certain proteins can be attributed to multiple cellular components, functions and/or processes. As shown in Fig. 2A, the 'biological processes' analysis revealed significant enrichment in platelet degranulation, innate immune response and cell adhesion. The analysis of 'molecular function' indicated that the differential CSF proteins were mainly associated with protein binding, calcium ion binding and serine-type endopeptidase activity (Fig. 2B). The 'cellular component' analysis (Fig. 2C) revealed that extracellular exosome, extracellular space and blood microparticle were the 
Table I. Differential proteins identified by label-free LC-MS/MS ordered by $\log _{2}$ FC.

\begin{tabular}{|c|c|c|c|}
\hline Protein ID & Gene name & Protein name & $\log _{2} \mathrm{FC}$ \\
\hline Q13822 & ENPP2 & Ectonucleotide pyrophosphatase/phosphodiesterase family member 2 & 5.32 \\
\hline Q16270 & IGFBP7 & Insulin-like growth factor-binding protein 7 & 4.97 \\
\hline P08294 & SOD3 & Extracellular superoxide dismutase & 4.29 \\
\hline O94985 & CLSTN1 & Calsyntenin-1 & 4.18 \\
\hline P09486 & SPARC & Secreted protein acidic and rich in cysteine & 4.13 \\
\hline P10643 & $\mathrm{C} 7$ & Complement component $\mathrm{C} 7$ & 4.11 \\
\hline P01210 & PENK & Proenkephalin & 3.95 \\
\hline P00736 & C1R & Complement $\mathrm{C} 1 \mathrm{r}$ & 3.94 \\
\hline Q08380 & LGALS3BP & Galectin-3-binding protein & 3.92 \\
\hline Q8WXD2 & SCG3 & Secretogranin-3 & 3.82 \\
\hline P02747 & C1QC & Complement $\mathrm{C} 1 \mathrm{q}$ subcomponent subunit $\mathrm{C}$ & 3.69 \\
\hline P14618 & PKM & Pyruvate kinase & 3.41 \\
\hline P16870 & CPE & Carboxypeptidase E & 3.33 \\
\hline $\mathrm{P} 00751$ & CFB & Complement factor B & 3.29 \\
\hline P05155 & SERPING1 & Plasma protease $\mathrm{C} 1$ inhibitor & 3.19 \\
\hline P09871 & $\mathrm{C} 1 \mathrm{~S}$ & Complement $\mathrm{C} 1$ s subcomponent & 3.14 \\
\hline P18065 & IGFBP2 & Insulin-like growth factor-binding protein 2 & 3.12 \\
\hline P01034 & CST3 & Cystatin-C & 3.11 \\
\hline P00450 & $\mathrm{CP}$ & Ceruloplasmin & 3.10 \\
\hline $\mathrm{P} 02751$ & FN1 & Fibronectin & 3.10 \\
\hline P05060 & CHGB & Secretogranin-1; CCB peptide & 3.08 \\
\hline Q92823 & NRCAM & Neuronal cell adhesion molecule & 3.08 \\
\hline Q15113 & PCOLCE & Procollagen $\mathrm{C}$ endopeptidase enhancer 1 & 3.03 \\
\hline Q12860 & CNTN1 & Contactin-1 & 2.95 \\
\hline P02766 & TTR & Transthyretin & 2.93 \\
\hline Q99435 & NELL2 & Neural epidermal growth factor-like like 2 & 2.92 \\
\hline P19652 & ORM2 & Alpha-1-acid glycoprotein 2 & 2.85 \\
\hline P02763 & ORM1 & Alpha-1-acid glycoprotein 1 & 2.84 \\
\hline P10909 & CLU & Clusterin & 2.77 \\
\hline O95502 & NPTXR & Neuronal pentraxin receptor & 2.64 \\
\hline P51693 & APLP1 & Amyloid-like protein 1; C30 & 2.60 \\
\hline Q12805 & EFEMP1 & EGF-containing fibulin-like extracellular matrix protein 1 & 2.58 \\
\hline P10645 & CHGA & Chromogranin-A & 2.46 \\
\hline P20774 & OGN & Mimecan & 2.44 \\
\hline P05067 & APP & Amyloid beta A4 protein & 2.33 \\
\hline O15240 & VGF & Neurosecretory protein VGF & 2.32 \\
\hline P55058 & PLTP & Phospholipid transfer protein & 2.32 \\
\hline Q14624 & ITIH4 & Inter-alpha-trypsin inhibitor heavy chain H4 & 2.31 \\
\hline Q92876 & KLK6 & Kallikrein-6 & 2.30 \\
\hline P01857 & IGHG1 & Ig gamma- 1 chain $\mathrm{C}$ region & 2.29 \\
\hline P24592 & IGFBP6 & Insulin-like growth factor-binding protein 6 & 2.27 \\
\hline O00533 & CHL1 & Neural cell adhesion molecule L1-like protein & 2.24 \\
\hline P01019 & AGT & Angiotensinogen & 2.19 \\
\hline P01860 & IGHG3 & Ig gamma-3 chain $\mathrm{C}$ region & 2.10 \\
\hline Q9NQ79 & CRTAC1 & Cartilage acidic protein 1 & 1.87 \\
\hline P02753 & RBP4 & Retinol-binding protein 4 & 1.84 \\
\hline P01009 & SERPINA1 & Alpha-1-antitrypsin & 1.79 \\
\hline O43505 & B4GAT1 & Beta-1,4-glucuronyltransferase 1 & 1.68 \\
\hline P25311 & AZGP1 & Zinc-alpha-2-glycoprotein & 1.52 \\
\hline Q14515 & SPARCL1 & SPARC-like protein 1 & 1.50 \\
\hline P13591 & NCAM1 & Neural cell adhesion molecule 1 & 1.34 \\
\hline Q9UBP4 & DKK3 & Dickkopf-related protein 3 & 1.27 \\
\hline P01834 & IGKC & Ig kappa chain $\mathrm{C}$ region & 1.14 \\
\hline
\end{tabular}

$\log _{2} \mathrm{FC}, \log _{2}$ fold change. 


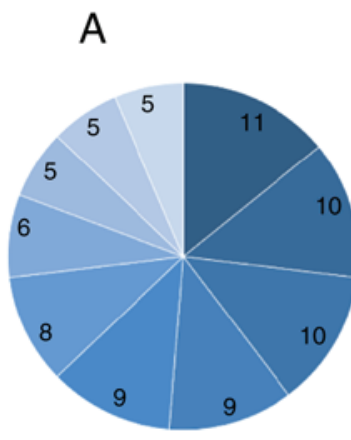

C

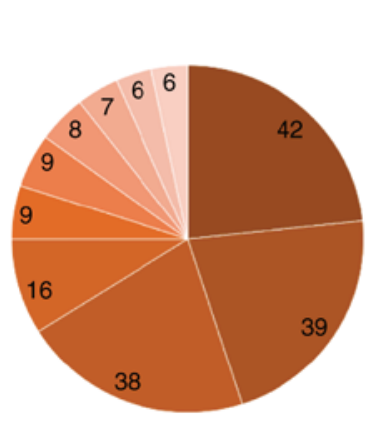

- Platelet degranulation

- Innate immune response

= Cell adhesion

- Complement activation

Complement activation,

classical pathway

= Proteolysis

Negative regulation of endopeptidase

activity

= Acute-phase response

" Regulation of cell growth

- Cellular protein metabolic process

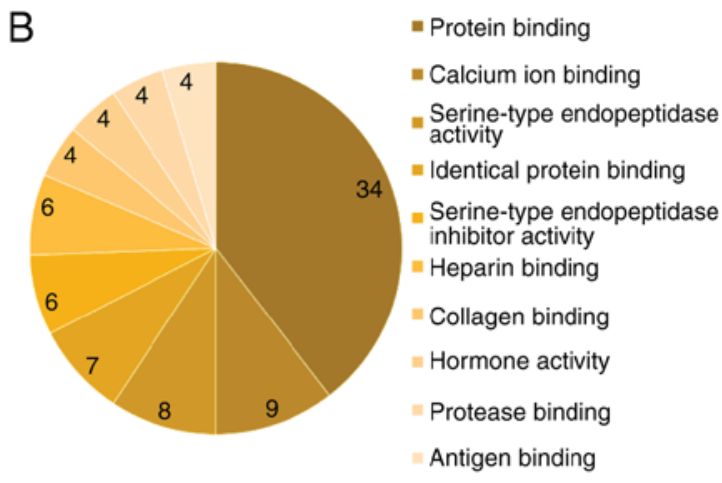

D

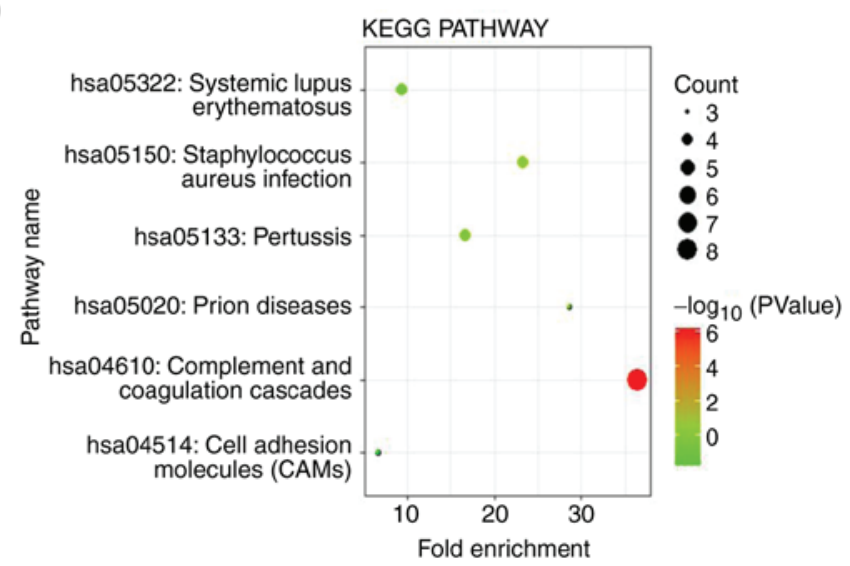

Figure 2. Global proteomics analysis of CSF with DLBCL. GO analysis based on the 53 differential proteins identified in DLBCL patients: (A) biological process; (B) molecular function; and (C) cellular component. (D) KEGG pathway analysis of all differential proteins. CSF, cerebrospinal fluid; DLBCL, diffuse large B-cell lymphoma; GO, Gene Ontology; KEGG, Kyoto Encyclopedia of Genes and Genomes.

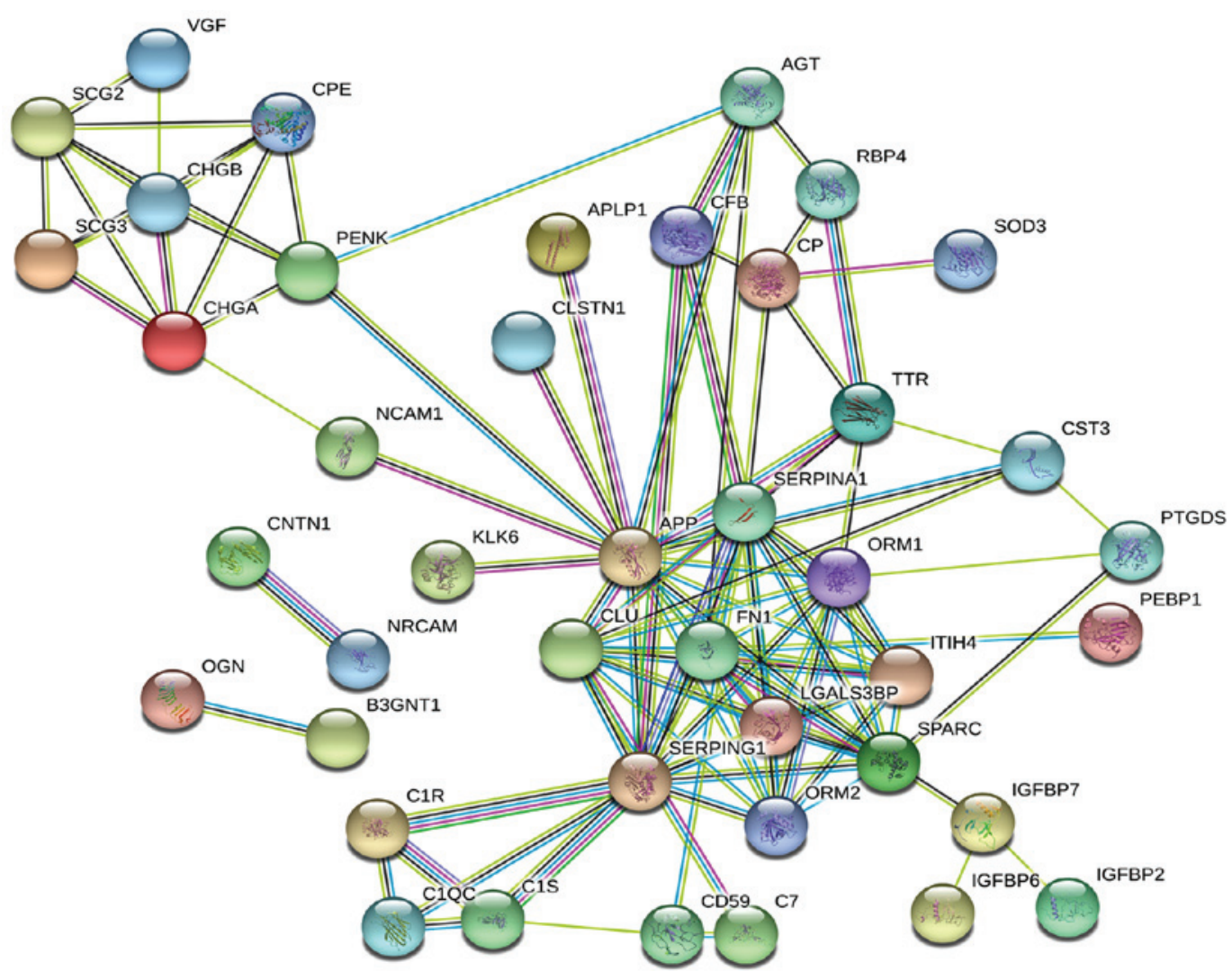

Figure 3. PPI network of differentially expressed proteins. The protein interactions network was constructed using online software (Search Tool for the Retrieval of Interacting Genes/Proteins). PPI, protein-protein interaction. 
Table II. Functional enrichment analysis of the hub modules.

\begin{tabular}{|c|c|c|c|c|}
\hline Module & Database & GO and pathway & Genes (n) & P-value \\
\hline \multirow[t]{5}{*}{1} & \multirow[t]{4}{*}{ GO term-BP } & Platelet degranulation & 9 & 0.15 \\
\hline & & Acute-phase response & 5 & $<0.01^{\mathrm{b}}$ \\
\hline & & Negative regulation of endopeptidase activity & 4 & $<0.01^{b}$ \\
\hline & & Cell adhesion & 3 & $0.02^{\mathrm{a}}$ \\
\hline & KEGG & Complement and coagulation cascades & 2 & $0.03^{\mathrm{a}}$ \\
\hline \multirow[t]{3}{*}{2} & \multirow[t]{3}{*}{ GO term-BP } & Neuropeptide signaling pathway & 2 & $0.02^{\mathrm{a}}$ \\
\hline & & Secretion & 3 & $0.02^{\mathrm{a}}$ \\
\hline & & G-protein coupled receptor signaling pathway & 3 & $0.03^{\mathrm{a}}$ \\
\hline
\end{tabular}

${ }^{\mathrm{a}} \mathrm{P}<0.05 ;{ }^{\mathrm{b}} \mathrm{P}<0.01$. GO, Gene Ontology; BP, biological process; KEGG, Kyoto Encyclopedia of Genes and Genomes.

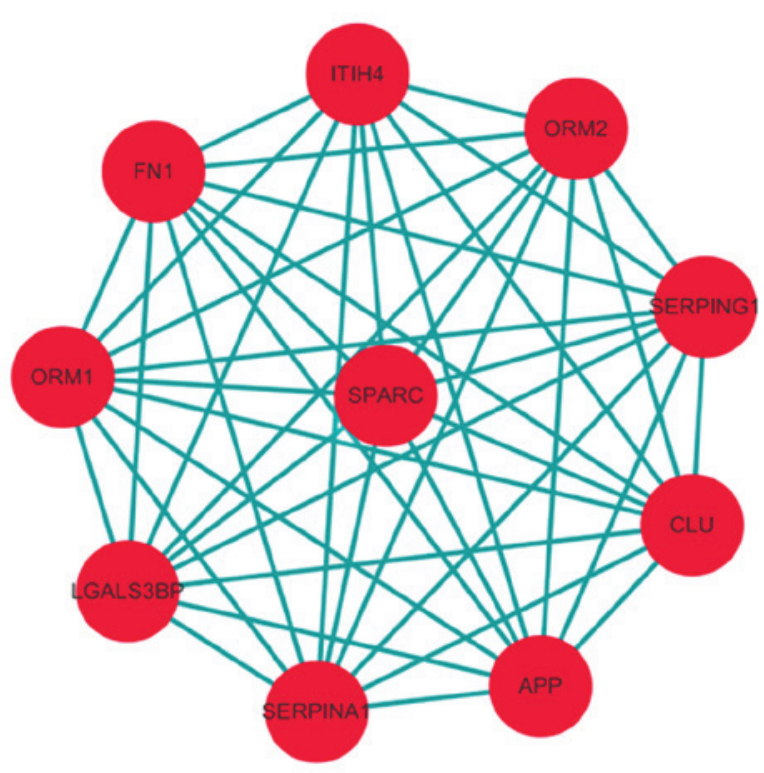

Module 1 (10 genes, 45 interaction)

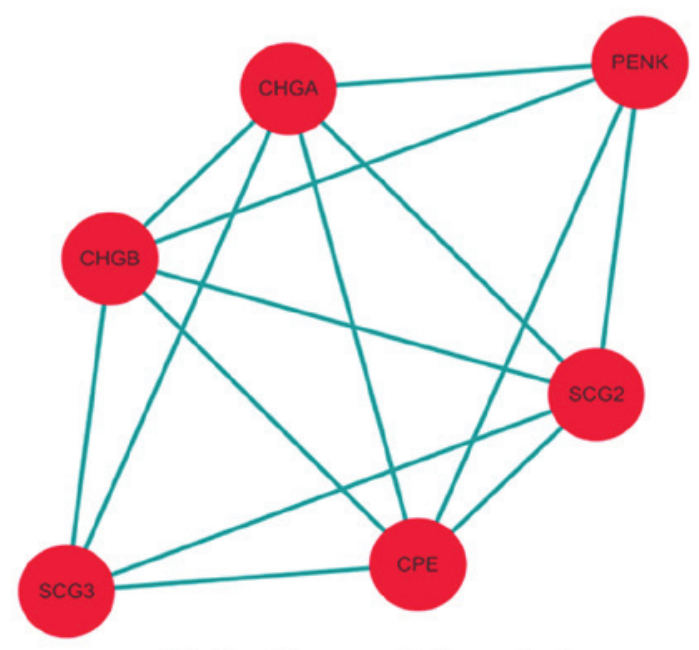

Module 2 (6 genes, 14 interaction)

Figure 4. Hub gene network modules. The number of genes and interactions of the hub gene network modules were analyzed using MCODE.

most over-represented terms $(\mathrm{P}<0.001)$. Kyoto Encyclopedia of Genes and Genomes pathway analysis revealed three canonical pathways: Complement and coagulation cascades, prion diseases and Staphylococcus aureus infection, which provided insight into the function of the 53 differential proteins in the CSF (Fig. 2D).

Protein-protein interaction (PPI) network (PPIN) construction. Based on the Search Tool for the Retrieval of Interacting Genes/Proteins (STRING) database, a PPIN of 53 proteins was constructed (Fig. 3). As shown in Fig. 4, two hub gene network modules were obtained from the PPIN analyzed by MCODE. There were 10 genes with 45 interactions in module 1 (MCODE score 8.182), and six genes with 14 interactions in module 2 (MCODE score 4). In order to further understand the function of the obtained hub modules, they were analyzed using the DAVID database (Table II). The first module was mainly enriched in platelet degranulation, and the complement and coagulation cascades. The second module was mainly related to neuropeptide signaling pathway and secretion. Furthermore, secreted protein acidic and rich in cysteine (SPARC) was found to be at the center of network module 1 with the highest fold change ( $\left.\log _{2} \mathrm{FC}: 4.13\right)$. In network module 2, proenkephalin (PENK) was the protein with the highest fold change ( $\left.\log _{2} \mathrm{FC}: 4.13\right)$. These findings indicated that the decreased expression of SPARC and PENK in the CSF was the most sensitive, and these proteins may serve as early-phase biomarkers to evaluate the risk of CNS involvement in DLBCL.

\section{Discussion}

In the present study, high-throughput quantitative proteomic analysis was applied to analyze the expression of proteins in the CSF of patients with DLBCL. Four CSF samples from patients with DLBCL with CNS involvement were compared with six CSF samples from healthy control subjects. Among the 53 differentially expressed proteins identified, the most significantly altered proteins, namely SPARC and PENK, appear to hold promise as a diagnostic biomarker to evaluate the risk of CNS involvement in DLBCL, as they exhibited the highest fold change and cross-talk with other proteins found to be altered in the CSF of patients with DLBCL.

SPARC is a 43-kDa glycoprotein, also referred to as BM-40 or osteonectin (33). SPARC is a multifunctional protein that 
can modulate extracellular matrix assembly, integrin activity and growth factor signaling (34-37). In cancer, SPARC has different functions, depending on the tissue and cell type. In certain types of cancer, such as melanoma and glioma, SPARC is associated with a highly aggressive tumor phenotype (38). However, in neuroblastomas, and ovarian, colorectal and primitive neuroectodermal tumors, SPARC-induced changes in the tumor microenvironment can suppress tumor progression $(38,39)$. It was previously reported that patients with DLBCL with any SPARC-positive cells in the microenvironment had a significantly longer overall survival, and patients with high SPARC-positivity in the microenvironment also had a significantly longer event-free survival (40). These findings suggested that SPARC-positive stromal cells in the microenvironment of DLBCL may act as tumor suppressors. In the present study, the expression of SPARC was also found to be significantly downregulated in the CSF of patients with DLBCL with CNS involvement, which was in accordance with the suppressive function of SPARC in DLBCL. The mechanism underlying the suppressive effect of SPARC on the progression of DLBCL and improved patient survival rates remains unclear. Possible explanations include the decreased production of necessary growth factors, alterations of the extracellular matrix preventing tumor cell interactions, and decreased integrin production by tumor cells, resulting in altered extracellular matrix interactions (40).

PENK is a nuclear protein responsive to growth arrest and differentiation signals, and is required for the induction of apoptosis (41). It is reported that the expression of PENK is downregulated by two proto-oncogenes, Fos and Jun (42). Previous studies have reported that PENK is downregulated in prostate cancer and glioblastoma; PENK was also reported to be aberrantly methylated in colorectal, bladder and pancreatic cancer (43-48). PENK has been shown to stimulate stress-activated apoptosis, particularly under treatment with chemotherapeutic drugs, in colon cancer. In the present study, PENK was found to be downregulated in the CSF of patients with DLBCL with CNS involvement. These findings suggest that the tumors may attenuate apoptosis by downregulating the protein expression of PENK.

Taken together, these data indicate that the decreased expression of certain proteins in the CSF of patients with DLBCL with CNS involvement is closely associated with the antitumor and/or anti-invasion process. Therefore, detecting the concentration of proteins, including SPARC and PENK, offers a potential method for identifying patients with DLBCL at risk of subsequent CNS involvement. In the present study, the small sample size is a limitation, but it also provides future direction to collect additional samples for further investigation.

In conclusion, through high-throughput label-free quantitative proteomic analysis of the CSF from patients with DLBCL and healthy control subjects, 53 differentially expressed proteins and two gene (protein) hub network modules were identified in total. Protein biomarkers, including SPARC and PENK, which were found to be closely associated with DLBCL invasion, were expressed at low levels in the CSF of patients with early-stage DLBCL. Therefore, they may be valuable biomarkers for assessing the risk of CNS involvement in DLBCL at initial diagnosis. Considering the potential limitations of the present study in terms of design, technique and analytical strategy, additional investigations with larger cohorts of patients are required to confirm the robustness of these findings.

\section{Acknowledgements}

Not applicable.

\section{Funding}

No funding was received.

\section{Availability of data and materials}

The datasets used and/or analyzed during the current study are available from the corresponding author on reasonable request.

\section{Authors' contributions}

XBL and XLM participated in the design of the studies. XBL and FM collected data from participants. $\mathrm{HZ}$ performed the statistical analysis; XBL and SZ participated in writing the manuscript and performed the literature search. All the authors have read and approved the final version of this manuscript for publication.

\section{Ethics approval and consent to participate}

All procedures performed in studies were in accordance with the ethical standards of the Medical Ethics Committee of West China Hospital, Sichuan University (2016.285). All participants underwent an informed consent process.

\section{Patient consent for publication}

Not applicable.

\section{Competing interests}

The authors declare that they have no competing interests.

\section{References}

1. A clinical evaluation of the International Lymphoma Study Group classification of non-Hodgkin's lymphoma. The Non-Hodgkin's Lymphoma Classification Project. Blood 89: 3909-3918, 1997.

2. Chen W, Wang H, Chen H, Liu S, Lu H, Kong D, Huang X, Kong Q and $\mathrm{Lu} \mathrm{Z}$ : Clinical significance and detection of microRNA-21 in serum of patients with diffuse large B-cell lymphoma in Chinese population. Eur J Haematol 92: 407-412, 2014.

3. Martelli M, Ferreri AJ, Agostinelli C, Di Rocco A, Pfreundschuh M and Pileri SA: Diffuse large B-cell lymphoma. Crit Rev Oncol Hematol 87: 146-171, 2013.

4. Feugier P, Van Hoof A, Sebban C, Solal-Celigny P, Bouabdallah R, Fermé C, Christian B, Lepage E, Tilly H, Morschhauser F, et al: Long-term results of the R-CHOP study in the treatment of elderly patients with diffuse large B-cell lymphoma: A study by the Groupe d'Etude des Lymphomes de l'Adulte. J Clin Oncol 23: 4117-4126, 2005

5. Pfreundschuh M: Therapy of diffuse large B-cell lymphomas. Eur J Cancer 1 (Suppl 45): S386-S387, 2009.

6. Feugier P, Virion JM, Tilly H, Haioun C, Marit G, Macro M, Bordessoule D, Recher C, Blanc M, Molina T, et al: Incidence and risk factors for central nervous system occurrence in elderly patients with diffuse large-B-cell lymphoma: Influence of rituximab. Ann Oncol 15: 129-133, 2004 
7. Herrlinger U, Glantz M, Schlegel U, Gisselbrecht C and Cavalli F: Should intra-cerebrospinal fluid prophylaxis be part of initial therapy for patients with non-Hodgkin lymphoma: What we know, and how we can find out more. Semin Oncol 36 (4 Suppl 2): S25-S34, 2009.

8. van Besien K, Ha CS, Murphy S, McLaughlin P, Rodriguez A, Amin K, Forman A, Romaguera J, Hagemeister F, Younes A, et al: Risk factors, treatment, and outcome of central nervous system recurrence in adults with intermediate-grade and immunoblastic lymphoma. Blood 91: 1178-1184, 1998.

9. Zinzani PL, Magagnoli M, Frezza G, Prologo G, Gherlinzoni F, Bendandi M, Albertini P, Babini L, D'Alessandro R and Tura S: Isolated central nervous system relapse in aggressive non-Hodgkin's lymphoma: The Bologna experience. Leuk Lymphoma 32: 571-576, 1999.

10. Hollender A, Kvaloy S, Nome O, Skovlund E, Lote K and Holte H: Central nervous system involvement following diagnosis of non-Hodgkin's lymphoma: A risk model. Ann Oncol 13: 1099-1107, 2002

11. Zahid MF, Khan N, Hashmi SK, Kizilbash SH and Barta SK Central nervous system prophylaxis in diffuse large B-cell lymphoma. Eur J Haematol 97: 108-120, 2016.

12. Haioun C, Besson C, Lepage E, Thieblemont C, Simon D, Rose C, Tilly H, Sonet A, Lederlin P, Attal M, et al: Incidence and risk factors of central nervous system relapse in histologically aggressive non-Hodgkin's lymphoma uniformly treated and receiving intrathecal central nervous system prophylaxis: A GELA study on 974 patients. Groupe d'Etudes des Lymphomes de l'Adulte. Ann Oncol 11: 685-690, 2000.

13. Barosi G, Carella A, Lazzarino M, Marchetti M, Martelli M, Rambaldi A, Tarella C, Vitolo U, Zinzani PL, Tura S, et al: Management of nodal diffuse large B-cell lymphomas: Practice guidelines from the italian society of hematology, the italian society of experimental hematology and the italian group for bone marrow transplantation. Haematologica 91: 96-103, 2006.

14. Boehme V, Zeynalova S, Kloess M, Loeffler M, Kaiser U, Pfreundschuh M, Schmitz N and German High-Grade Non-Hodgkin's Lymphoma Study Group (DSHNHL): Incidence and risk factors of central nervous system recurrence in aggressive lymphoma-a survey of 1693 patients treated in protocols of the German High-Grade Non-Hodgkin's Lymphoma Study Group (DSHNHL). Ann Oncol 18: 149-157, 2007.

15. Hill QA and Owen RG: CNS prophylaxis in lymphoma: Who to target and what therapy to use. Blood Rev 20: 319-332, 2006.

16. Liang R, Chiu E and Loke SL: Secondary central nervous system involvement by non-Hodgkin's lymphoma: The risk factors. Hematol Oncol 8: 141-145, 1990

17. Fletcher CD and Kahl BS: Central nervous system involvement in diffuse large B-cell lymphoma: An analysis of risks and prevention strategies in the post-rituximab era. Leuk Lymphoma 55 2228-2240, 2014.

18. Holte H, Leppä S, Björkholm M, Fluge O, Jyrkkiö S, Delabie J, Sundström C, Karjalainen-Lindsberg ML, Erlanson M, Kolstad A, et al: Dose-densified chemoimmunotherapy followed by systemic central nervous system prophylaxis for younger high-risk diffuse large B-cell/follicular grade 3 lymphoma patients: Results of a phase II Nordic Lymphoma Group study. Ann Oncol 24: 1385-1392, 2013.

19. Penalver FJ, Sancho JM, de la Fuente A, Olave MT, Martín A, Panizo C, Pérez E, Salar A, Orfao A and Spanish Lymphoma Group (GELTAMO): Guidelines for diagnosis, prevention and management of central nervous system involvement in diffuse large B-cell lymphoma patients by the Spanish Lymphoma Group (GELTAMO). Haematologica 102: 235-245, 2017.

20. Glass JP, Melamed M, Chernik NL and Posner JB: Malignant cells in cerebrospinal fluid (CSF): The meaning of a positive CSF cytology. Neurology 29: 1369-1375, 1979.

21. Hegde U, Filie A, Little RF, Janik JE, Grant N, Steinberg SM, Dunleavy K, Jaffe ES, Abati A, Stetler-Stevenson M and Wilson WH: High incidence of occult leptomeningeal disease detected by flow cytometry in newly diagnosed aggressive B-cell lymphomas at risk for central nervous system involvement: The role of flow cytometry versus cytology. Blood 105: 496-502, 2005.

22. McMillan A, Ardeshna KM, Cwynarski K, Lyttelton M, McKay P, Montoto S and British Committee for Standards in Haematology: Guideline on the prevention of secondary central nervous system lymphoma: British committee for standards in haematology. Br J Haematol 163: 168-181, 2013.
23. Villa D, Connors JM, Shenkier TN, Gascoyne RD, Sehn LH and Savage KJ: Incidence and risk factors for central nervous system relapse in patients with diffuse large B-cell lymphoma: The impact of the addition of rituximab to CHOP chemotherapy. Ann Oncol 21: 1046-1052, 2010.

24. Shimazu Y, Notohara K and Ueda Y: Diffuse large B-cell lymphoma with central nervous system relapse: Prognosis and risk factors according to retrospective analysis from a single-center experience. Int J Hematol 89: 577-583, 2009.

25. Scott BJ, Douglas VC, Tihan T, Rubenstein JL and Josephson SA A systematic approach to the diagnosis of suspected central nervous system lymphoma. JAMA Neurol 70: 311-319, 2013.

26. Shen X, Young R, Canty JM and Qu J: Quantitative proteomics in cardiovascular research: Global and targeted strategies. Proteomics Clin Appl 8: 488-505, 2014.

27. Weisser H, Nahnsen S, Grossmann J, Nilse L, Quandt A Brauer H, Sturm M, Kenar E, Kohlbacher O, Aebersold R and Malmström L: An automated pipeline for high-throughput label-free quantitative proteomics. J Proteome Res 12: 1628-1644, 2013.

28. Gitau EN, Kokwaro GO, Karanja H, Newton CR and Ward SA: Plasma and cerebrospinal proteomes from children with cerebral malaria differ from those of children with other encephalopathies. J Infect Dis 208: 1494-1503, 2013

29. Ou Q, Liu X and Cheng X: An iTRAQ approach to quantitative proteome analysis of cerebrospinal fluid from patients with tuberculous meningitis. Biosci Trends 7: 186-192, 2013.

30. Pasinetti GM, Ungar LH, Lange DJ, Yemul S, Deng H, Yuan X, Brown RH, Cudkowicz ME, Newhall K, Peskind E, et al: Identification of potential CSF biomarkers in ALS. Neurology 66: 1218-1222, 2006

31. Priola GM,Foster MW, Deal AM, Richardson BM, Thompson JW and Blatt J: Cerebrospinal fluid proteomics in children during induction for acute lymphoblastic leukemia: A pilot study. Pediatr Blood Cancer 62: 1190-1194, 2015.

32. Rardin MJ, Newman JC, Held JM, Cusack MP, Sorensen DJ, Li B Schilling B, Mooney SD, Kahn CR, Verdin E and Gibson BW: Label-free quantitative proteomics of the lysine acetylome in mitochondria identifies substrates of SIRT3 in metabolic pathways. Proc Natl Acad Sci USA 110: 6601-6606, 2013.

33. Chlenski A and Cohn SL: Modulation of matrix remodeling by SPARC in neoplastic progression. Semin Cell Dev Biol 21: 55-65, 2010.

34. Bradshaw AD, Puolakkainen P, Dasgupta J, Davidson JM, Wight TN and Helene Sage E: SPARC-null mice display abnormalities in the dermis characterized by decreased collagen fibril diameter and reduced tensile strength. J Invest Dermatol 120: 949-955, 2003

35. Raines EW, Lane TF, Iruela-Arispe ML, Ross R and Sage EH: The extracellular glycoprotein SPARC interacts with platelet-derived growth factor (PDGF)-AB and -BB and inhibits the binding of PDGF to its receptors. Proc Natl Acad Sci USA 89: 1281-1285, 1992.

36. Sangaletti S, Stoppacciaro A, Guiducci C, Torrisi MR and Colombo MP: Leukocyte, rather than tumor-produced SPARC, determines stroma and collagen type IV deposition in mammary carcinoma. J Exp Med 198: 1475-1485, 2003.

37. Weaver MS, Workman G and Sage EH: The copper binding domain of SPARC mediates cell survival in vitro via interaction with integrin beta1 and activation of integrin-linked kinase. J Biol Chem 283: 22826-22837, 2008.

38. Tai IT and Tang MJ: SPARC in cancer biology: Its role in cancer progression and potential for therapy. Drug Resist Updat 11: 231-246, 2008

39. Bhoopathi P, Chetty C, Gujrati M, Dinh DH, Rao JS and Lakka S: Cathepsin B facilitates autophagy-mediated apoptosis in SPARC overexpressed primitive neuroectodermal tumor cells. Cell Death Differ 17: 1529-1539, 2010.

40. Meyer PN, Fu K, Greiner T, Smith L, Delabie J, Gascoyne R, Ott G, Rosenwald A, Braziel R, Campo E, et al: The stromal cell marker SPARC predicts for survival in patients with diffuse large B-cell lymphoma treated with rituximab. Am J Clin Pathol 135: 54-61, 2011

41. Bottger A and Spruce BA: Proenkephalin is a nuclear protein responsive to growth arrest and differentiation signals. J Cell Biol 130: 1251-1262, 1995.

42. Sonnenberg JL, Rauscher FJ III, Morgan JI and Curran T: Regulation of proenkephalin by Fos and Jun. Science 246: $1622-1625,1989$. 
43. Ueki T, Toyota M, Skinner H, Walter KM, Yeo CJ, Issa JP, Hruban RH and Goggins M: Identification and characterization of differentially methylated $\mathrm{CpG}$ islands in pancreatic carcinoma. Cancer Res 61: 8540-8546, 2001.

44. Fukushima N, Sato N, Ueki T, Rosty C, Walter KM, Wilentz RE, Yeo CJ, Hruban RH and Goggins M: Aberrant methylation of preproenkephalin and p16 genes in pancreatic intraepithelial neoplasia and pancreatic ductal adenocarcinoma. Am J Pathol 160: 1573-1581, 2002.

45. Goo YA, Goodlett DR, Pascal LE, Worthington KD, Vessella RL, True LD and Liu AY: Stromal mesenchyme cell genes of the human prostate and bladder. BMC Urol 5: 17, 2005.

46. Tan AC, Jimeno A, Lin SH, Wheelhouse J, Chan F, Solomon A Rajeshkumar NV, Rubio-Viqueira B and Hidalgo M: Characterizing DNA methylation patterns in pancreatic cancer genome. Mol Oncol 3: 425-438, 2009.
47. Roperch JP, Incitti R, Forbin S, Bard F, Mansour H, Mesli F, Baumgaertner I, Brunetti F and Sobhani I: Aberrant methylation of NPY, PENK, and WIF1 as a promising marker for blood-based diagnosis of colorectal cancer. BMC Cancer 13: 566, 2013.

48. Lee EJ, Rath P, Liu J, Ryu D, Pei L, Noonepalle SK, Shull AY, Feng Q, Litofsky NS, Miller DC, et al: Identification of global DNA methylation signatures in glioblastoma-derived cancer stem cells. J Genet Genomics 42: 355-371, 2015.

(2) This work is licensed under a Creative Common

EY NO NO Attribution-NonCommercial-NoDerivatives 4.0 International (CC BY-NC-ND 4.0) License. 